\title{
DAS NARRATIVAS DO CINECLUBE EM CÁCERES ÀS NARRATIVAS DA ESCOLA INDÍGENA LUTUMA DIAS: a educação escolar indígena diferenciada
}

\author{
OF THE NARRATIVES OF THE CINECLUBE IN CÁCERES TO THE \\ NARRATIVES OF THE INDIGENOUS SCHOOL LUTUMA DIAS: the \\ differentiated indigenous pertaining to school education
}

\section{DE LAS NARRATIVAS DEL CINECLUBE EN CÁCERES A LAS NARRATIVAS DE LA ESCUELA INDÍGENA LUTUMA DIAS: la educación escolar indígena diferenciada}

\author{
Naine Terena de Jesus \\ Doutora em educação. Bolsista PNPD Capes no Programa de Pós-graduação em Educação \\ da Universidade do Estado de Mato Grosso (UNEMAT-MT) \\ Cuiabá - MT, Brasil \\ naineterena@hotmail.com \\ Maritza Maldonado \\ Professora Adjunta da Universidade do Estado de Mato Grosso (UNEMAT-MT) \\ no curso de Pedagogia e no Programa de Pós-Graduação em Educação. \\ maritzacmaldonado@gmail.com
}

\begin{abstract}
Resumo: Este artigo foi produzido no âmbito do Projeto Cineclubes - Cinema, infâncias e diferenças, realizado pelo Ateliê de Imagem e educação, do Programa de Pós-graduação em Educação da UNEMAT - MT. As narrativas acerca dos povos indígenas do Brasil, apresentadas por professores participantes do Cineclube, movimentaram o pensamento das autoras para a releitura da tese de doutorado Audiovisual na Escola Terena Lutuma Dias: educação indígena diferenciada e as mídias, cujo foco era a problematização sobre a educação escolar indígena e o uso do audiovisual, em especial, para o ensino da cultura indígena e principalmente se este seria um material didático capaz de contemplar as necessidades pedagógicas dos professores Terena, frente aos recursos como livros e cartilhas que estão atualmente disponíveis na escola indígena. Revisitar a tese e trazer tais informações a este artigo, se deu devido ao fato das narrativas do Cineclube se tornarem personagens conceituais para se pautar a educação escolar indígena visando enriquecer o conhecimento do leitor acerca de diferentes contextos e realidades da educação no país.
\end{abstract}

Palavras-chave: Educação indígena. Interculturalidade. Tic. Infância. Indígenas.

\begin{abstract}
This article was produced in the scope of the participation of the authors in the Cineclubes Project - Cinema, childhoods and differences, carried through for the Studio of Image and education, of the Program of Graduate Course in Education of the UNEMAT - MT. The narratives concerning the indigenous people of Brazil, presented by participants teachers of the Cineclube, put into motion the thoughts author for the thesis recover of doctorate audio-visual at School Terena Lutuma Dias: indigenous education differentiated and the medias, whose angle was the problematic about the indigenous education, the use of the audiovisual, in special, for the teach of the indigenous culture and mainly if this would be a didactic material capable to consider the educationals necessities of Terena teachers, front to the resources as books and cartilhas that they are available at indigenous school. To revisit the thesis and to bring such information to this article, if gave due to the fact of the narratives of the Cineclube if to become highly regarded characters to point the indigenous pertaining to school education aiming at to enrich the knowledge of the reader concerning different contexts and realities of the education in the country.
\end{abstract}

Keyworks: Indigenous education. Interculture. Tic. Childhood. Indigenous.

Resumen: Este artículo fue reproducido en el marco del Proyecto Cineclubes - Cine, infancias e y diferencias, realizado por el Ateliê de Imagem y educación, del Programa de Pós-graduación en Educación de UNEMAT - MT. Las narrativas acerca de los pueblos indígenas del Brasil, presentadas por los profesores participantes del Cineclube, movieron el pensamiento de la autora: para la relectura de la tesis de doctorado Audiovisual en la Escuela Terena Lutuma Dias: educación indígena diferenciada y, los medios, cuyo foco era la problematización sobre la educación en particular, para la enseñanza de la cultura indígena y principalmente si éste sería un material didáctico capaz de contemplar las necesidades pedagógicas de los profesores Terena, frente a los recursos como libros y cartillas que actualmente están disponibles en la escuela indígena. Revisar el texto, y traer tal información a este artículo se ha dado por el hecho de las

Artigo recebido em setembro de 2017

Aprovado em novembro de 2017

Cad. Pesq., São Luís, v. 24, n. 3, set./dez. 2017 
narraciones de Cineclube, se convertieron en personajes conceptuales para pautar la educación escolar indígena con el objetivo de enriquecer el conocimiento del lector acerca de diferentes contextos y realidad de la educación en el país.

Palabras clave: Educación indígena. Interculturalidad. Tic. Infancia. Indígenas.

\section{INTRODUÇÃO}

O Projeto Cineclubes - Cinema, infâncias e diferenças vem sendo realizado desde o começo de 2016 na cidade de Cáceres - Mato Grosso, e é organizado pelo Ateliê de Imagem e Educação (AIE) do Programa de Pós-graduação em educação da UNEMAT - Campus Cáceres. O objetivo do projeto é que os professores da rede de ensino de Cáceres tenham um espaço para problematizar concepções de infâncias e diferença a partir de imagens e sons produzidos no cinema, promover formas de pensamentos outros, diferentes do que vem sendo pensado e praticado na educação escolar.

A cada sessão, um filme é utilizado como motivador para problematizações sobre as infâncias, sendo essas sessões gravadas e posteriormente transcritas por membros do AIE. Ao se inscreverem no projeto, os professores da rede de ensino de Cáceres, preenchem um formulário e um documento que autoriza a utilização de suas narrativas nas atividades desenvolvidas pelo grupo de pesquisa. No contexto do Ateliê de Imagem e educação, a autora deste artigo desenvolve pesquisa de pósdoutorado e, como os demais membros, se utiliza das transcrições para realizar as atividades propostas na sua produção acadêmica.

Cabe ressaltar que essas narrativas realizadas pelos educadores são compreendidas pelo grupo de pesquisa como personagens conceituais, conforme explicam Deleuze e Guattari (2010), ao dizerem que os personagens conceituais desestabilizam o plano de imanência instaurado e criam meios para que outros conceitos sejam criados.

Dessa forma, ressalta-se que, durante a leitura das transcrições das Sessões de Cineclube realizadas em 2016, algumas narrativas enfatizaram a conjuntura da educação escolar indígena a partir da experiência dos professores que as narraram, levando as autoras a propor uma releitura da tese de doutorado escrita por Naine Terena de Jesus e trazer para o cerne deste artigo a temática indígena no intuito de oferecer mais informações e corroborar para a visualização de diferentes aspectos que permeiam a educação e as comunidades indígenas no Brasil.

Por fim, esclarece-se que temos dois momentos na constituição do artigo: o primeiro, onde apresentamos brevemente as narrativas realizadas pelos nossos personagens conceituais - retiradas do Cineclube realizado pelo Grupo Ateliê de Imagem e Educação em Cáceres - Mato Grosso no ano de 2016, e o segundo que traz a revisão da tese de doutorado concluída em 2014, onde foram coletadas falas de 15 professores indígenas Terena da Aldeia indígena Limão Verde, localizada no município de Aquidauana - Mato Grosso do Sul, através de entrevistas gravadas em áudio e vídeo.

2 NARRATIVAS: percepções de professores não indígenas quanto a educação escolar indígena e suas peculiaridades

As narrativas apresentadas neste item correspondem ao Cineclube realizado no dia 26 de abril de 2016, ocorrido na cidade de Cáceres. Nesta data, foram projetados o filme Das crianças Ikpeng para o mundo e $\mathrm{O}$ amendoim da cotia, onde posteriormente as falas foram transcritas $\mathrm{e}$ compartilhadas pelos membros do Ateliê de Imagem e educação.

Este artigo, entretanto, não se trata da experiência do Cineclube em si, mas o tem como potencializador para a apresentação de algumas peculiaridades de uma escola indígena, e neste caso destaca-se a presença das Tecnologias de comunicação e informação enquanto materiais didáticos presentes na escola indígena Lutuma Dias, localizada na aldeia Limão Verde - município de Aquidauana - MS, já que os três relatos apresentados abaixo abordam algumas impressões dos professores quanto a educação escolar indígena, conforme apresentados a seguir.

[...] eu sempre tive curiosidade de conhecer uma aldeia indígena e o ano passado, em companhia com a assessora pedagógica de Pontes e Lacerda, nós fomos conhecer duas aldeias indígenas, ali no município de Nova Lacerda, e tava tendo problema lá, que os alunos, os indígenas, as crianças não queriam estudar e nós fomos até ali. A Secretária do município, da educação do município, mais a assessora pedagógica e eu, fomos até lá dar uma olhada e o interessante, com relação ao filme também, é que o professor é branco e os alunos não queriam assistir a aula. $A$ 
escola era mais aberta do que a escola do filme e ele estava lá ensinando a língua portuguesa pra eles e não a língua indígena como no filme. O professor reclamava a questão que quando iniciava a aula e alguém saia da aldeia pra ir pra cidade, que eles vão muito na cidade, tem carro, ai então eles vão pra cidade, as crianças simplesmente pulavam a cerquinha e corria e entrava no carro e iam pra cidade. Então, ele não estava conseguindo passar os conteúdos, não estava conseguindo dar a aula dele e, inclusive, nas duas aldeias é professor branco [...] Eu pude perceber no filme que sendo professor indígena também, irmãos, eles passam mais tempo na sala de aula, ali eles participam, desenham, conversam, aprendem [...] É interessante isso! Então, eu acho que o problema daquelas aldeias, que as crianças não querem estudar, talvez seria isso, que tem um professor branco ali e eu pude também conhecer, que lá também tem pessoas que já fez o magistério, que não fez a faculdade ainda, mas pessoas que terminou o 30 ano e poderia, talvez, tá dando aula lá nessa aldeia. (Participante Cineclube 1, 26 de abril de 2016).

Eu fiquei encantada com o processo de ensino e aprendizagem, né? É todo voltado pra cultura. Quando eles estão lá aprendendo a ler [...] No primeiro filme eles estão falando do amendoim, então, é voltada pra um conceito que eles vivem, por um conceito histórico deles, aonde eles estão, a forma que eles vivem e como é rico. Eu sempre... a gente trabalhar o conceito que a criança traz de casa, a vivência né? Então, enriquece muito o ensino e aprendizagem e lá nas duas deu pra perceber que eles trabalham totalmente... a escola trabalha totalmente voltada para a cultura, para o tempo, né? O passado como era, o agora e isso enriquece muito as aulas. (Participante Cineclube 2, 26 de abril de 2016).

Eu não sei se é essa palavra realmente, por exemplo, eu penso que a gente vai incorporando o novo e, às vezes, a gente esquece o que era nosso. Eu vejo nas escolas que a gente, assim, pouco os alunos conhecem o nosso siriri, o nosso cururu. A gente usa muito as danças agora que tá na moda, que eles vêm e tudo mais. Mas eu vejo, assim, me chamou a atenção para ver o novo, usar o novo sem deixar de viver também aquilo que era, que já é nosso, que já era nosso, que a gente conhece também. Então, é tentar colocar os dois na vida das crianças, na vida escolar. Eu vi por ai, por essa parte, achei muito rica essa questão do que entrou na cultura deles, mas que eles preservavam muito o que as avós falavam, o que os mais velhos colocavam pra eles, né? (Participante Cineclube 3, 26 de abril de 2016).

Ao observar os três relatos, verifica-se que trazem as impressões que professores não indígenas tiveram do cotidiano indígena, motivados pelo bate papo do Cineclube após a projeção dos filmes $\mathrm{O}$ amendoim da cotia e das Crianças lkpeng para o mundo. Tais impressões foram ressaltadas, também, a partir da vivência que esses professores tiveram com povos indígenas no decorrer da vida, ou ainda pela construção da identidade dos povos originários no imaginário desses educadores.

Ressalta-se que atualmente existem cerca de 260 povos no território nacional, e esses povos mantém modos de vidas distintos, falando cerca de 140 idiomas diferenciados. Debates como os motivados pelo Cineclube são espaços propícios para que se possa verificar as formas de subjetivações acerca dos povos indígenas e que quase sempre essas subjetivações não consideram a diversidade e peculiaridades de cada povo, trazendo nos diálogos o índio genérico1 - aquele que é construído a partir das informações dos livros didáticos e meios de comunicação de massa.

No caso das narrativas acima, percebe-se que os professores trazem algumas impressões sobre a escola indígena, de que este espaço é voltado para o contexto interno das aldeias, ao mesmo tempo em que se apropriam de conhecimentos outros, oriundos da sociedade envolvente. É este eixo de pensamento que move a escrita deste artigo, pois os professores, ao assistir os dois filmes, se colocam a interpretar e refletir sobre a escola indígena e suas problemáticas, o que dialoga com a tese de doutorado em educação, constituída de relatos de professores Terena que trazem informações pertinentes acerca de como se constitui uma de muitas outras escolas indígenas do país.

Dessa forma, se prossegue a escrita, agora adentrando ao tema principal do artigo, a apresentação de uma escola indígena diferenciada e sua relação com o audiovisual. Cabe frisar que a constituição de informações para a tese e transpostas neste artigo se deu a partir do levantamento de documentos e arquivos acerca da implantação da escola indígena na aldeia Limão Verde, e aqui

\footnotetext{
1 O índio genérico é aquele construído ao longo dos 517 anos de invasão do Brasil, onde, se tem a imagem de que todos os indígenas vivem da mesma forma, falam o mesmo idioma e mantém os mesmos hábitos e forma de vida, o que não corresponde a realidade dos povos indígenas do Brasil.
} 
faço uma breve cronologia da implantação da educação escolar entre os Terena desta aldeia e, por fim, a atuação dos professores na escola indígena diferenciada.

Complementam-se os dados com as anotações realizadas no caderno de campo durante os quatro anos da pesquisa de doutorado, onde acompanhou-se também a utilização dos livros didáticos fornecidos pela Gerência de educação do município, jogos e outros materiais disponíveis na escola, assim como as atividades didáticas desenvolvidas na escola Lutuma Dias.

\subsection{A aldeia Limão Verde}

A aldeia Limão Verde está localizada no município de Aquidauana, em Mato Grosso do Sul. De acordo com Oliveira (1976) "a aldeia Limão Verde existe desde a Guerra do Paraguai e foi fundada por João Dias, bandeirante paulista que vivia com uma índia Terena" (OLIVEIRA, 1976, p. 80). Narrativas dos moradores da aldeia apresentam outras versões dos fatos, como é o caso do ancião Isac Dias, que em visita a campo explica que a aldeia foi constituída por seu bisavô e não por João Dias. Esse fato se alinha ao que Jesus (2007) disserta sobre as memórias individuais e coletivas, respaldada por ponderações de Pollack, onde os 'constitutivos da memória individual ou coletiva movimentam as narrativas de Isac, que em primeiro lugar, relembra os acontecimentos vividos pessoalmente e em segundo lugar, são os acontecimentos vividos por tabela; acontecimentos vividos pelo grupo ou pela coletividade a qual a pessoa se sente pertencer.

De acordo com as narrativas de Isac, o que ocorreu foi o deslocamento de famílias Terena do Êxiva2 para a região de Aquidauana, onde trabalharam com João Dias, o bandeirante paulista, citado por Roberto Cardoso de Oliveira. Entre eles estava seu avô, fundador da aldeia Limão Verde, que posteriormente levou outros Terena para a região (narração oral para a pesquisadora Naine Jesus, gravado em vídeo em 2005).

Residem na aldeia e seus núcleos mais de 1.600 indígenas, segundo os dados apresentados pelo Cacique em 2012 e impresso na placa de identificação da aldeia. A área foi demarcada através do Decreto n 795 de 1928 do Governo do Estado do Mato Grosso, tendo este documento registrado cerca de 2.500 hectares aos indígenas do Limão Verde.

Em relatório, o antropólogo Gilberto Azanha (2001) escreve que no ano de 1990, houve vários deslocamentos dos Terena de Limão Verde a Brasília, ocasião em que a FUNAI criou um Grupo Técnico para regularizar em definitivo a situação fundiária desta Reserva e no ano de 1998, o Ministro da Justiça declarou a área delimitada pelo Grupo de Trabalho em 4.886 hectares, como 'de ocupação tradicional indígena'. No ano de 2001 a FUNAI começou a pagar as benfeitorias para retirada dos chacareiros.

Aárea de Limão Verde passou a ter uma superfície de 5.377 hectares, tendo sua homologação em 10 de fevereiro de 2003. Em setembro de 2011, foram reintegrados 392 hectares da Fazenda Santa Bárbara, que desde 1996 estava em processo de julgamento. A área foi declarada terra indígena de acordo com os laudos antropológicos e argumentos apresentados pela Funai e em meados de 2016 essa área foi novamente foco das ações judiciais por parte do Fazendeiro que requereu a área embasado na prerrogativa do Marco Temporal.

$\mathrm{Na}$ localidade existem duas escolas, sendo uma gerenciada pela Prefeitura Municipal de Aquidauana e a outra pelo Governo do Estado de Mato Grosso do Sul. Ambas as escolas já contam com professores Terena, sendo a escola de nível Fundamental dirigida e coordenada por Terenas da aldeia, inclusive sendo gerido agora por um professor com doutorado, efetivado no concurso realizado no ano de 2016.

Nesta aldeia a principal fonte de renda é a agricultura, seguido do serviço militar, da changa3 e da escola. A agricultura familiar é um a característica cultural dos Terena, que a utilizam para o consumo próprio e também para a comercialização nas cidades de Aquidauana e Campo Grande. Alguns moradores da comunidade recebem benefícios governamentais como: cesta básica, bolsa escola, salário maternidade.

\section{EDUCAÇÃO ESCOLAR NA ALDEIA LIMÃO VERDE}

A história da educação escolar na Aldeia Limão Verde tem início em 1931, com a atuação da irmã Corina Niccócio, motivada pela presença da igreja católica na aldeia. Segundo Cardoso (apud

2 O Êxiva é constituído por regiões do Chaco Paraguaio, Boliviano e algumas localidades de Mato Grosso do Sul, habitados pelos antigos Terena.

3 Trabalhos temporários, geralmente nas fazendas que estão na região de Aquidauana. 
MARQUES, 2009), Corina formou uma turma de 20 alunos, nas dependências da Igreja Católica localizada no centro da aldeia. De acordo com Projeto Político Pedagógico da escola indígena Lutuma Dias, Corina lecionou no Ensino Primário até o ano de 1941. Após a irmã, explica Cardoso (2011), no início da década de 1940, o Terena Lúcio Dias lecionou por cerca de quatro anos. Esse trabalho não foi remunerado. Nos anos seguintes a Prefeitura de Aquidauana contratou três professores: dois deles eram não indígenas e o terena Pascoal Dias. Outro terena de Limão Verde que lecionou nesse período foi Valério Martins, que era remunerado pela Missão evangélica Uniedas. A presença dos professores indígenas acabou sendo excluída com a justificativa de falta de formação, o que os impediu de continuarem em suas funções no ano de 1947.

A primeira unidade escolar oficial da aldeia foi criada através da Lei Municipal $n^{\circ} 032$ de 27 de outubro de 1948. Em 1982, através de um convênio firmado entre a Prefeitura municipal e a Funai, foi construída a sede definitiva da Escola Municipal de Primeiro Grau Limão Verde, prédio da atual escola Lutuma Dias. Tinha inicialmente duas salas de aula e um banheiro masculino e outro feminino. Sua ampliação ocorreu no ano de 1991, ganhando mais salas de aula, cozinha e secretaria. Foi no ano de 1991 que a escola também passou a se chamar Escola Municipal Indígena Lutuma Dias4.

Em 1997 os indígenas ocuparam de forma massiva as salas de aulas das diferentes aldeias Terena do município. Foi neste mesmo ano que muitos deles concluíram o ensino superior. No ano de 1999, Aquidauana criou a Lei Municipal $n^{\circ} 1.701 / 99$, que alteraria a denominação das escolas municipais, incluindo o termo "indígena" para as escolas localizadas em área territorial onde estavam localizados os indígenas Terena.

$\mathrm{Na}$ reforma realizada em 2009 , foram feitos reparos estruturais nas seis salas de aula, sala de professores e quadra esportiva. Atualmente a Escola Indígena Lutuma Dias conta com 25 professores. Desses dez professores indígenas, cinco são concursados. A escola abriga estudantes da Pré-escola até o Ensino Fundamental. Os demais servidores como cozinheiros, serviços gerais, secretárias, direção e coordenação, também são membros da comunidade Limão Verde. Além da escola municipal, a aldeia conta com a Escola Estadual de ensino médio Pascoal Leite Dias, o que evita o deslocamento dos alunos para outras localidades do município.

\section{ESCOLA INDÍGENA, DIFERENCIADA E O AUDIOVISUAL}

A implementação da escola indígena diferenciada é um desafiado que vem sendo enfrentado pelos diversos povos indígenas brasileiros. As dificuldades são distintas e em diversos setores: currículo, formação de professores indígenas, infraestrutura, espaço e tempo da infância indígena versus espaço tempo escolar, entre outros. Além das dificuldades em comum, muitas escolas mantém ritmos e percursos próprios, como é o caso da Escola indígena Lutuma Dias.

Quando no relato coletado no Cineclube, o Professor 1 enfatiza que acredita que o problema daquelas aldeias onde as crianças não querem estudar, esteja relacionado ao fato do professor ser branco, ressalta-se que na escola Lutuma Dias as reflexões sobre a presença do professor não indígena alcança mais o âmbito das políticas internas e inserção profissional dos professores indígenas na concepção da escola indígena, do que a rejeição de alunos a professores não indígenas. Ao citar as políticas internas, deseja-se explanar que a comunidade deseja ter um quadro de professores totalmente Terena para que princípios e elementos da cultura Terena, sejam introduzidos na gestão e condução da escola, pois acredita-se que os professores indígenas vivenciam e compreendem a vida de seus alunos indígenas.

Já as falas dos professores 2 e 3 se conectam a questão que permeia a escola diferenciada: privilegiar os conteúdos da grade curricular da escola formal agregando o conhecimento indígena. A escola trabalha totalmente voltada para a cultura, para o tempo, né? (Professor 2). Este trecho denota o que o corpo técnico e docente da Escola Lutuma Dias pretende concretizar. Porém, como grande parte das escolas indígenas, existe a dificuldade em se propor alterações no Projeto Político Pedagógico e propor ações que perpassem todas as disciplinas.

É nesse conjunto que os professores Terena buscam conhecer diferentes formas de fixar uma educação escolar Terena. Para isso necessitam criar formas de conciliar o conteúdo proposto no projeto curricular com a vivência na aldeia. De acordo com suas narrativas, somente os livros didáticos não são capazes de contemplar este anseio, daí a utilização das tecnologias de comunicação e informação (TIC) como suportes didáticos.

4 Informações do Projeto Político Pedagógico da Escola Indígena Lutuma Dias de 2002. 
Porém, a utilização de Tic por indígenas (não somente na escola, mas de forma geral) suscita alguns questionamentos que acompanham tais povos há décadas: muitas pessoas imaginam que a inserção de todo e qualquer recurso externo à cultura indígena é um indício do desaparecimento desta cultura. Esse tipo de pensamento tem sua fundamentação em visões estereotipadas que se prolongam por anos, causando um estranhamento com relação aos povos indígenas, como explica Munduruku (2012, p. 14):

Usando penas, despido, corpo pintado, empunhando arco e flecha, entre outras imagens. Essas imagens costumam dar um quê de fantasia de espanto, terror e medo o que faz com que as pessoas continuem repetindo estereótipos e alimentando um distanciamento sempre perigoso, pois joga as populações indígenas a um patamar de humanidade desprezível.

Para romper com esses estereótipos é necessário compreender a história da colonização brasileira, e a partir dela apreender as diversas situações de resistência promovidas pelos povos indígenas brasileiros. Cunha (1980) faz essa marcação histórica dos povos indígenas, destacando alguns momentos. O primeiro é o do contato com o não indígena que levou doenças diversas e dizimou populações às vezes em tais proporções que se tornaria impossível uma recuperação demográfica.

Numa segunda etapa, criou-se uma dependência, onde essas sociedades necessitariam de tecnologias não-indígenas como as enxadas, espingardas, anzóis, cachaça, panelas e principalmente o dinheiro, para a sobrevivência material5. Após este período, implantou-se uma imagem depreciativa do indígena, a ponto de se envergonharem de seus próprios ritos e modo de vida - tornam-se acaboclados e renegam, em sua maioria, a origem indígena.

Em um último processo, Cunha (1980) enxerga os indígenas antes "acablocados, envergonhados", declarando-se novamente indígenas, retomando rituais, reaprendendo uma língua indígena esquecida entre outras formas de retomada da identidade antes abdicada.

Num grifo próprio proponho se pensar um momento posterior a esses citados por Carneiro. O momento contemporâneo, no qual os povos indígenas sentem a necessidade de dominar toda e qualquer tecnologia externa em prol da sua manutenção da sua forma de vida e dos aspectos que permeiam a vida de suas comunidades. Seria o momento de se apropriar do que lhes foi oferecido antes para a destruição cultural e física, para agora ser utilizada em prol da sobrevivência e da retomada de seus territórios originais. Para isso, demonstram que a cultura está em movimento, e que o acesso a diferentes tecnologias não os tornam menos indígenas.

Dimensiono meu grifo a partir das falas de Machado (2007), que explica que os indígenas deixam de ser apresentados como objetos passivos e passam a garantir a preservação não mais da "pureza étnica ou cultural", mas de sua autonomia política e de sua opção por um modelo de vida diferenciado, identificando-se como indígenas perante os brancos, como povos com tradições próprias, e sendo sujeitos de registros - antes o que era realizado pelo olhar do outro agora se torna elemento para a visualização de si mesmo.

Sobre a cultura não ser algo estática, Canclinni (2009, p. 41-42) escreve:

Não é algo que apareça sempre da mesma maneira. Daí a importância que adquiriram os estudos sobre recepção e apropriação de bens e mensagens nas sociedades contemporâneas. Mostram como um mesmo objeto pode transformar-se através de usos e reapropriações sociais. $\mathrm{E}$ também, ao nos relacionarmos uns com os outros, aprendemos a ser interculturais.

Para Canclinni (2009, p. 41), estamos em "constante processo social de produção, circulação e consumo da significação na vida social, daí o fato de não caracterizar a cultura como algo imutável." Ao observar os relatos realizados pelos professores da Escola indígena Lutuma Dias, verifica-se que a explanação de Machado é pertinente:

A comunidade nacional esta muito perto da gente hoje né, não tem como fugir dela mais[...] nós temos que estar preparado pra inserir, ou trabalhar com eles em harmonia, penso que também por exemplo aqui na aldeia limão verde estamos a $20 \mathrm{~km}, 18 \mathrm{~km}$ da cidade e na verdade eles estão dentro da nossa casa, assistindo televisão, dvd, acho que só falta entrar aqui o ar condicionado. Temos várias tecnologias que estão dentro da nossa aldeia, é impossível a gente não inserir alguma coisa que a gente possa, possamos entender que ele vai nos auxiliar nos nossos trabalhos, auxiliar

5 Essa dependência diz respeito a inserção de novos instrumentos de trabalho, os vícios e do dinheiro, pois, a partir do momento em que tem contato com essas tecnologias outras, alguns povos indígenas se viam dependente delas, em especial do dinheiro e das bebidas alcoólicas . 
para nossos alunos, para que esses alunos tenham uma visão de que existe uma ponte de ida e vinda, para que possamos viver lá fora e viver aqui dentro. (Professora 1, abril de 2013).

A preocupação em colocar o aluno em contato com a vida dentro e fora da aldeia permeia quase todas as entrevistas realizadas - a formação da identidade. Além deste fator, detecta-se que para alcançar este objetivo os professores necessitam de suportes que sejam suficientemente eficazes para a preparação desses alunos, e ele não sofra interferências na sua consciência indígena ao mesmo tempo em que tenha conhecimentos suficientes para dialogar com os não indígenas.

Para verificar como os professores se relacionam com a questão da identidade Terena, coletei alguns relatos perguntando a eles quais características diferenciavam a educação Terena das demais. De forma geral, explicam que a educação indígena Terena está expressa na linguagem corporal e na formação moral a partir do respeito a memória indígena. Exemplificam dizendo que o olhar dava as dicas de como a criança deveria agir e o respeito pelos mais velhos.

Salientam que o respeito aos mais idosos e a divisão entre "o mundo dos adultos e o mundo das crianças" foram fatores importantes para a educação de cada um deles, que acreditam que esses elementos da educação indígena são fundamentais dentro da escola indígena, inclusive diferenciando-as das escolas da cidade. É possível descrever essas informações repassadas na entrevista, nos trechos abaixo:

Nasci e cresci (na aldeia [...] muitas vezes os pais nos ensinam a respeitar, não deixava a gente intrometer na conversa dos adultos. (Professor B, abril de 2013).

É uma educação totalmente diferente das crianças da cidade. As crianças da cidade na sua grande maioria são crianças que têm muitas coisas [...] eu vejo assim, que a educação das nossas crianças, a educação indígena, com essa interação entre os não índios, isso veio mudando alguma coisa [...] Em relação à família, quando a família da gente reunia para conversar não aceitava a gente perto. Então a gente sabia quando a gente tinha que se afastar dali apenas com o olhar que a gente tinha que sair dali senão a coisa ia pegar depois. (Professor C, abril de 2013).

[...] eu penso que nós temos essa vivência em grupo e é muito bom, a família, essa experiência que a gente tem, a questão da comunidade que a gente tem, esse é o lado bom de estar aqui. Imagina se meus filhos estivessem lá na cidade? Ai você vê a preocupação com o movimento, com a violência [...] até mesmo você vê a condição na sala de aula, às vezes não e necessário falar alto. É muito mais fácil trabalhar na área indígena. Por que você vê muitos professores até brigam para vir para cá. Por que acho que nossa educação e diferente, eu não sei né, por que eles dizem que nas escolas da cidade não tem condições de trabalhar, enquanto aqui é só falar, olha pessoal, por mais que esteja fazendo bagunça, parou. (Professora D, abril de 2013).

A partir das falas verifica-se a importância da convivência familiar e a opinião dos mais velhos. Situar a vida na aldeia como sendo um elemento importante na formação da criança indígena é outro fator que se mostra presente no interior das falas. Entendo que ao falarem do espaço da aldeia, não trata-se apenas de uma disposição físico-geográfica. Relaciona-se ao espaço simbólico e tudo que o ser indígena e o espaço da memória indígena ocupa. Hall (2002, p. 72) propõe uma problematização a partir da concepção de que todas as identidades estão localizadas em "espaços e tempos simbólicos, as geografias imaginárias: encontram lugar no senso de lugar, de lar, em mitos de origem que projetam o presente de volta ao passado, em narrativas de nação que conectam o indivíduo a eventos históricos mais amplos, mais importantes."

A memória do espaço e a importância dos territórios para os indígenas permeiam as preocupações dos professores com relação ao conteúdo ministrado na escola. Cientes da invisibilidade histórica dos povos indígenas nos materiais didáticos, esses professores tem o entendimento de que é necessário narrar a história do seu povo no território brasileiro. Em interface a outros temas, acreditam também que em outros setores da vida as contribuições e o modo de ver o mundo dos Terena deveria ser apresentado como um conteúdo a ser estudado na escola voltada a eles. Em entrevista, chego a esta problemática, e pergunto sobre o que pensam do livro didático, obtendo as seguintes respostas:

De arte Terena não tem. Só o livro mesmo que eu queria que tivesse o livrinho só para nós. É, só para nós. (Professora B, abril de 2013).

Olha, seria interessante a gente tá (pausa) buscando algum outro jeito de a gente relacionar algumas atividades que dá para gente estar voltado para a questão Terena, por que não existe 
nenhum tipo de material exclusivo elaborado para nós, e acho que vamos ter que fazer um. (Professora C, abril de 2013).

Na minha opinião não (não são bons os livros didáticos), porque não é a realidade de nossas aldeias [...]. (Professor D, abril de 2013).

O livro de Língua Portuguesa, eu utilizo mais pra exercícios e leituras, eu acho os textos muito longo pra eles. Se tivesse um livro didático direcionados para alunos indígenas, por que nós temos são textos que não são do conhecimentos dos alunos não é de nossa realidade, e para quem tem dificuldades, isso se torna um ponto mais obscuros para eles ainda, nossos livros são muito complexo pra eles. (Professora A, abril de 2013).

Sim, são, mas na maneira que falei aquela hora, mais pra pesquisas, mas deveria elaborar livros mais da comunidade. Tipo uma metodologia aqui própria da aldeia. (Professor E, abril de 2013).

Melhorar o material didático, de acordo com a realidade da aldeia. (Professora F, abril de 2013).

Os livros didáticos que vieram esse ano está sendo bom, só que no caso assim, a gente tem que se adaptar né, no nosso cotidiano, não aceitar tudo que é imposto para nós, o que esta no livro. (Professora G, abril de 2013).

Diante da ausência de uma maior representatividade indígena, em específico Terena, no material de estudo oficial, questionou-se outros materiais utilizavam em sala de aula:

Às vezes a gente precisa usar livros, né? Mas a maioria eu trago anotado no caderno e na aula de Educação Física só jogos. (Professor F, abril de 2013).

Todos. Livros, cadernos, jogos, tudo que for necessário para o aprendizado dos alunos. (Professora J, abril de 2013).

Livros, cadernos, textos, textos da internet, textos fora do livro didáticos, quadro de giz, aquilo que você tem de material pra usar na área indígena. (Professora A, abril de 2013).

Procuro trabalhar mais com os livros, por exemplo, os daqui mesmo feito na aldeia. Por exemplo, nós temos livros que fizemos no curso de magistério pelo povos do pantanal; que a gente fez e se chama etno matemática que através das pesquisas dos anciãos, a gente elaborou esse livro e que esta sendo muito importante pra trabalhar aqui na sala de aula. Veio uma caixa de papelão de livros para escola e para todas as escolas indígenas de Mato Grosso do Sul. (Professor G, abril de 2013).

A gente inventa né, EVA, os desenhos as pinturas, todas essas coisas né. Cadernos, joguinhos de letrinha, tudo isso, o que nós temos né. (Professora D, abril de 2013).

Jornais, caixas de Papelões e outros. (Professora H, abril de 2013).

Livros, cadernos, jogos, filmes, hoje mesmo eu trouxe filmes das questões indígenas, pois desde cedo eles tem de aprender a compreender as questões indígenas para já começar a lutar pelos seus direitos. (Professora F, abril de 2013).

Eu uso livros, mas agora eu estou trabalhando com jogos mesmo, para as crianças pegarem e, assim bastante, letrinhas. Dominó, quebra-cabeça, alfabeto móvel, agora números móveis, trabalhar com bingo, o nome deles, produção de texto, tudo dentro dos jogos. O alfabeto móvel são as letras do alfabeto separadinhas. Ou a gente confecciona ou tem que comprar. (Professora N, abril de 2013).

Na pré-escola, muitos livros com contos e mitos locais, revistas com imagem sobre esporte, higiene, jogos pedagógicos com números e letras, meio ambiente e o uso de data show. No $4^{\circ}$ ano o mesmo material, incluindo o uso de cadernos, passando para os alunos trabalhos como tarefas, tabuada, para ajudar o professor regente nessa matéria, em sala de aula, jogos cognitivos com números e letras, na quadra de esporte, atividades motoras e jogos lúdicos, sem o futebol. Uso de cartolinas para fazerem trabalhos sobre a Educação Física e datas comemorativas, fazendo a correção de português auxiliando os alunos e o professor nessa disciplina. (Professor $\mathrm{B}$, abril de 2013).

Os professores esclarecem em suas falas que estão em busca de materiais que se adequem ao ritmo de aprendizagem e o espaço tempo da escola Lutuma Dias. Daí a utilização de recursos diversos. Em alguns momentos houveram as ponderações sobre a saída com os alunos para aulas de campo, porém essa possibilidade nem sempre é possível, já que a proposta curricular da escola quase sempre impossibilita que os alunos se retirem do espaço escolar. Seguido desses relatos sobre os materiais utilizados dentro da escola, indago sobre a utilização do audiovisual, obtendo as seguintes respostas: 
Sim, já usei. Eu passei aquele que você trouxe aqui, acho que é DVD, que era meu pai que tava falando. (Professora C, abril de 2013).

Sim, o que falta para nós aqui são dvd's, alguns recursos. O último filme foi agora na semana do índio quando eu coloquei para eles, eles já tinham assistido na televisão, o filme Tayná, como é quinto ano, eu programei exercícios para que eles pudessem assistir o filme e pudessem dar retorno tanto em sala de aula como em testes e provas, eles guardarem o que realmente aquele filme queria dizer para eles. (Professora D, abril de 2013).

Já levei sim. Bom resultado sim, porque depois dos vídeos, a gente faz uma alta discussão sobre o tema, agente apenas não assiste, mas faz uma alta reflexão do tema e faz debates. (Professor F, abril de 2013).

Sim já levei, pra Aldeia Córrego Seco onde leciono trabalhei com esses vídeos. Porque os alunos gostaram desse material. Eles cobram sempre o uso de filmes, eu nunca trabalhei, mas pretendo trabalhar com data show. (Professor G, abril de 2013).

Sim, bastante, eles até incentivam a gente a procurar assuntos voltados a questão (indígena). (Professora I, abril de 2013).

Sim por exemplo, se eu for passar [...] eu uso assim vídeo bastante nas aulas de ciência por que a gente trabalha bastante com a natureza e higiene. Aí eu trabalho com filmes e na área de Educação Física também eu trabalho com o respeito, a amizade, com as crianças. Sim, com certeza antes de passar o filme primeiro comenta por que vai assistir e após o filme vai perguntar o que assistiram, o que aprenderam. E outra, trabalhar com título do filme, personagem, quem participou do filme é importante, é interessante trabalhar com isso. (Professora N, abril de 2013).

Do conjunto de falas apresentadas acima, algumas ponderações são pertinentes para se refletir. Uma delas diz respeito à própria escolha dos professores pelo audiovisual. Povos indígenas originariamente tem características orais. Se antes sentavam-se no pátio da aldeia ou no espaço de suas moradias para ouvir histórias, agora a televisão ocupa um local de transmissão de informações através da imagem e som mediada pelos equipamentos tecnológicos. A respeito dessa similaridade com a cultura tradicional um dos professores relata:

Elas (as crianças) adoram (os filmes), principalmente quando o professor deixa o aluno livre para assistir, no sentido de, no meu caso, podem sentar ao chão ou deitar quem quiser. (Professor B, abril de 2013).

O professor ressalta que os alunos se sentem bem ao poderem quebrar as regras das cadeiras alinhadas das salas de aula, para poderem se sentar ou deitar aleatoriamente perto da TV, assim como acontece nos pátios da aldeia.

Outro ponto a se ressaltar é a possibilidade de visualizar contextos semelhantes aos seus nas ficções são objetivos dos professores. Buscar propagar a memória Terena é um anseio, então os vídeos, em especial os indígenas, possibilitam a identificação dos alunos os povos originários e reforçam a importância da memória ancestral.

No contexto da memória e identidade vemos que existe uma grande demanda dos professores em materiais que representem e atualizem os alunos no que diz respeito as lutas indígenas e a importância da coletividade.

[...] devemos trazer coisas que é daqui da comunidade [...] por exemplo assim, tipo, na hora de pegar um conteúdo que é lá da emenda, mas tipo assim, trazer em outro cotidiano, que tem tudo a ver na sala de aula a realidade da nossa comunidade. (Professor 7 G, abril de 2013).

Muitas vezes eu levo para sala, as causas voltadas para a questão indígena, na semana passada trabalhei com o $4^{\circ}$ ano a questão da água voltada para o meio ambiente, os nossos rios, tanto que eu trouxe aqui pra eles o vídeo sobre o rio São Francisco, pra eles verem que não é só aqui que esta acontecendo essa degradação do leito do rio, então esta no modo geral e se a gente cuidar aqui conscientizar isso, acho que vai melhorar muito, trabalhando a questão indígena, o meio ambiente e a comunidade em si. (Professora I, abril de 2013).

Através das fotografias, principalmente com os pequenininhos, nós não podemos estar assim, saindo numa distância tão longe, devido muitas coisas né, por exemplo, aqui na nossa aldeia temos muito cerrado, muitas pedras altas, onde temos que passar quando a gente sai para fazer uma fotografia, em relação a fotografia é bom que o próprio professor, registra e leva para os alunos a fotografia, e através da fotografia os alunos poderá perceber esse local, esse tema que nós estamos pesquisando. (Professora B, abril de 2013). 
Na pré-escola, foi o filme Avatar. Na época que passei o filme, estávamos em processo de paralisação das aulas, devidos a retomadas de terras. Ao assistirem o filme, citei o exemplo do que estava acontecendo, e os alunos comentaram em casa que já sabiam por que estávamos acampados brigando por terras. Isso me deixou muito feliz, porque os pais me vieram falar que ficaram felizes por que os filhos entenderam a briga da causa das terras. (Professor C, abril de 2013).

As narrativas acima ponderam o quanto os professores se dedicam a falar dos ensinamentos da educação indígena, àquela que quase sempre não encontra espaço nas escolas, pois estas necessitam cumprir um currículo e um Projeto Político Pedagógico que não contempla esse aprendizado.

Tratando um pouco desse tema, em especial na Escola indígena Lutuma Dias, o Projeto Político Pedagógico é uma construção datada em 2000 e não passou por nenhuma alteração nos últimos anos. Outra questão é que as únicas referências a proposição de escola diferenciada, se dá na presença das disciplinas de Arte e língua Terena, que não são capazes de contemplar todos os aspectos da cultura Terena e sua profundidade. Isso porque, o currículo acompanha a formatação das escolas urbanas, onde o conteúdo, a carga horária e disciplinas são iguais. As exceções são realizadas no contexto da escola indígena, como foi o caso da retomada de terras, em que houve a paralisação das aulas, e dentro do conteúdo os professores procuraram contextualizar os alunos sobre o que ocorria na escola.

Em conversa com o professor $\mathrm{C}$, que projeto o filme Avatar, notei que era a possibilidade de uma contra-informação, já que, no momento da tensão de retomadas de terras, as principais informações que circulavam nas cidades próximas eram oriundas dos grandes veículos de comunicação local, que quase sempre são aportados por políticos e fazendeiros da região. A contra informação no contexto escolar, encadeia-se nas proposições de Soares (2011) que afirma ser necessário o olhar crítico para as mídias, sendo isso possível somente quando os estudantes começam a ter outras referências, que não a mídia tradicional, e sim, a introdução de materiais distintos na escola.

Neste contexto, as informações repassadas eram quase sempre em oposição ao movimento dos indígenas o que poderia levar os alunos a negarem as ações dos adultos, colocando-os no patamar em que as mídias os colocava: invasores e baderneiros.

Reunindo todas essas informações e verificando o discurso da produção de materiais próprios, no ano de 2013 propus uma oficina de elaboração de conteúdos Terena para a escola indígena. A ação foi realizada através do Observatório da Educação Indígena, no qual integrei o Projeto Momentos e lugares da Educação indígena, coordenado pela prof. Dra. Circe Bittencourt, na PucSP.

Realizamos algumas ações de formação e reuniões para elaboração de conteúdos que resultaram em dois vídeos e uma cartilha. A atuação dos educadores nesses vídeos foi diretamente na coleta de informações e no contato com pessoas que pudessem ser registradas falando sobre comidas tradicionais e pajés. Posteriormente acompanharam a captação de imagens, ofereceram ilustrações, fotografias e demais conteúdos que ilustraram a cartilha e os vídeos.

O grupo escolheu os temas que gostariam de ver retratados e foram obter informações para a construção do roteiro e produção da cartilha. Dentre os temas estava a apresentação dos xamãs Terena. Aideia era registrar a história desses membros das comunidades, devido ao desaparecimento destes líderes espirituais no decorrer dos tempos. A experiência tocou profundamente os professores, que assumiram ter também, uma visão estereotipada sobre eles:

Eu achei muito interessante essa história de pajé por que quando a Janete entrevistou a Lipé, parecia um filme que passou na minha cabeça, e a Janete contava história do pai dela, do vô dela [...] aquele dia puxa vida, agora sim eu falei, eu quero ir fundo nessa história de pajelança. (Professora J, abril de 2013).

O outro vídeo produzido abordou as comidas tradicionais Terena. Os professores assumiram a função de produtores do vídeo, escolhendo as personagens, quais alimentos seriam feitos, onde buscar os alimentos. A comida é um elemento importante na cultura Terena, pois, este é um povo que se dedica a agricultura familiar. Seus alimentos em grande parte são oriundos das próprias roças, e essas plantações, são também escoadas para venda na cidade próxima.

Já a cartilha trouxe temas como ervas medicinais, a história dos xamãs Terena, a estória do pé de garrafa e as comidas típicas. Nas duas produções, percebi a facilidade em desenvolverem a 
narrativa audiovisual. A parte escrita levou mais tempo, pois, faziam questão que fosse um material escrito em língua portuguesa e Terena.

Avaliando os relatos, pude aferir que o audiovisual tem distintas funções dentro da escola Lutuma Dias, porém, para ao realizarem as produções próprias, saliento um outro aspecto: as experiências de captação de imagens e sons, construção de roteiros, produção, os colocou em um ponto diferente do simples expectador. Puderam lançar seus olhares para a própria realidade e dar o tom da fala aos seus produtos. Para Rivas "apropriar-se das tecnologias, da língua e da escrita pode ser encarado como uma forma de 'devorar' o outro, deter os conhecimentos e 'poderes' da cultura estrangeira com a qual nos relacionamos" (RIVAS, 2012, p. 23). Esse 'devorar' citado por Rivas, pode ser relacionado à capacidade de lidar com a nova geração Terena, que já domina com facilidade os elementos tecnológicos e também, estar em diálogo com a sociedade não indígena, através desses aparatos, incluindo aí, a internet e suas redes sociais.

\section{CONSIDERAÇÕES FINAIS}

Ao revisitar a tese de doutorado impulsionada por uma atividade que estou desenvolvendo no momento, me fez rever alguns conceitos e impressões acerca das infâncias e processos de escolarização. Por um lado, percebe-se a importância que os espaços dos Cineclubes tem em fazer o pensamento a pensar sobre questões que permeiam a educação escolar no país e os filmes como intercessores, tem alcançado as concepções e clichês formados no mundo cultural dos educadores das escolas urbanas, o que possibilita proporcionar debates e outros pensamentos e desmistificar informações que até o momento eram tidas como únicas verdades, principalmente no que diz respeito aos povos indígenas brasileiros.

A partir dos relatos dos professores participantes do Cineclube em Cáceres - MT, foi possível acessar as construções realizadas sobre o funcionamento de uma escola em área indígena e o olhar para o conjunto de concepções que se estabeleceram acerca dos indígenas brasileiros. Trazer o contexto dos Terena para este artigo, torna-se importante para ampliar as problematizações sobre as peculiaridades de cada escola indígena, e de como os produtos audiovisuais tem se apresentado como potencializadores de outras formas de ensino.

Se nas escolas não-indígenas brasileiras, a utilização dos aparatos tecnológicos são bastante recente e fazem parte de um projeto educomunicativo em andamento, imagina-se que essa utilização seria mais expressiva nas cidades para depois alcançar as aldeias. Porém, o que se vê no país é a proliferação de utilização do audiovisual e outras tecnologias de comunicação por indígenas, que realizam anualmente uma série de produções de conteúdos independentes, sendo este um fenômeno que merece atenção, principalmente quando estas produções adentram às escolas indígenas.

Por fim, a experiência de se alinhavar narrativas de contextos totalmente diferentes, é enriquecedora no que concerne em problematizar processos educacionais como um todo, sendo o exercício proposto na escrita deste artigo, um dos mecanismos encontrados por seus autores para que as diferentes pesquisas reverberem cada vez mais em textos e produções acadêmicas que se dedicam a problematizar a educação no país. 


\section{REFERÊNCIAS}

AZANHA, G. As terras indígenas Terena no Mato Grosso do Sul. Brasília, DF: Centro de Trabalho Indigenista, 2001.

CANCLINI, N. G. Culturas híbridas: estratégias para entrar e sair da modernidade. Tradução Heloisa Pezza Cintrão, Ana Regina Lessa. 4. ed. reimp. São Paulo: Edusp, 2009.

CARDOSO, W. D. A história da educação escolar para o Terena: origem e desenvolvimento do ensino médio na aldeia Limão Verde. 2011. 143 f. Tese (Doutorado em História das Sociedades lbéricas e Americanas) - Pontifícia Universidade Católica do Rio Grande do Sul, Porto Alegre, 2011.

CUNHA, Manoela Carneiro. Da metamorfose dos índios. Folhetim. p.11, 1980, disponível em https:// documentacao.socioambiental.org/noticias/anexo noticia/43443_20171020_091754.PDF, acessado em 18 de nov. de 2017.

DELEUZE, G.; GUATTARI, F. O que é filosofia? Tradução Bento Prado Jr., Alberto Alonso Muñoz. São Paulo: Editora 34, 2010.

Palácio da Presidência do Estado de Mato Grosso, Cuiabá, Decreto $n^{\circ} 795$, de 06 de fevereiro de 1928, caixa 085. Aquidauana: Câmara Municipal de Aquidauana - BPRAM.

HALL, S. A identidade cultural na pós-modernidade. Tradução Tomaz Tadeu da Silva, Guaraci Lopes Louro. 11. ed. Rio de Janeiro: DP\&A, 2002.

JESUS, N. T. de. Kohixoti-Kipaé, a dança da Ema: memória, resistência e cotidiano Terena. 2007. 132 f. Dissertação (Mestrado em Artes)- Universidade de Brasília, Brasília, DF, 2007.

Câmara Municipal de Aquidauana. Lei Municipal $\mathrm{n}^{\circ}$ 032 , de 27 de outubro de 1948. Cria escolas indígenas no município de Aquidauana. Prefeitura Municipal de Aquidauana, em 27 de outubro de 1948, disponível em http://www.cmaquidauana.ms.gov.br/ legislacao/leis-de-1947-a-2012/item/1886-lei-032. html acessado em 18 nov. 2018.

Câmara Municipal de Aquidauana. Lei Municipal $n^{0}$ 1.701 de 19 de abril de 1999 - Aquidauana-MS, altera a denominação das Escolas Municipais situadas em área territorial pertencente à reserva indígena, incluindo-se o termo Indígena, e passam a ser denominada Escola Municipal Indígena. . Prefeitura Municipal de Aquidauana. disponível em http:// www.cmaquidauana.ms.gov.br/legislacao/leis-de1947-a-2012/item/2971-lei-1701.html, acessado em 18 nov. 2018.

MACHADO, A. (Org.). Made in Brasil: três décadas do vídeo brasileiro. São Paulo: Iluminuras; Itaú Cultural, 2007.

MARQUES, C. N. Memória Terena: história, cultura, identidade e resistência. 2009. 90 f. Trabalho de Conclusão de Curso (Licenciatura em História)Universidade Federal de Mato Grosso do Sul, Aquidauana, 2009.

MUNDURUKU, D. Literatura indígena e as novas tecnologias da memória. LEETRA Indígena, São Carlos, v. 1, n. 1, 2012.

OLIVEIRA, R. C. de. Do índio ao bugre: o processo de assimilação dos Têrena. Rio de Janeiro: Livraria F. Alves, 1976.

RIVAS, E. D. Dispositivos tecnológicos de mediação, hibridização cultural e processos comunicativos na Reserva Indígena de Dourados e entre os Ayoreo do Paraguai. 2012. 209 f. Tese (Doutorado em Comunicação e Semiótica) - Pontifícia Universidade Católica de São Paulo, São Paulo, 2012.

SOARES, I. de O. Educomunicação: o conceito, o profissional, a aplicação: contribuições para a reforma do ensino médio. São Paulo: Paulinas, 2011. 